\title{
Rural urban differential in Transactional sex among unmarried (Not in Union) Young Women (15-24 years) in Uganda
}

\section{Vincent Okotel ( $\square$ okotelv29@gmail.com )}

Makerere University College of Business and Management Sciences

\section{Robert Wamala}

Makerere University

Martin Kayitale Mbonye

Makerere University College of Business and Management Sciences

\section{Research}

Keywords: Transactional sex, Young women, Oaxaca Blinder decomposition, Not in union

Posted Date: September 22nd, 2020

DOI: https://doi.org/10.21203/rs.3.rs-78871/v1

License: (c) (i) This work is licensed under a Creative Commons Attribution 4.0 International License.

Read Full License 


\section{Abstract}

Background: Transactional sex, a causal exchange of gifts, money and services for sex is practiced globally. Transactional sex is associated with risky sexual behaviors, unintended pregnancy, gender based violence and HIV infection. Proportionally in 2016, TS among young women not in union in Uganda was almost twice in rural areas (16.4\%) compared to urban (8.9\%) areas. Despite the negative consequences associated with transactional sex, no study in Sub-Saharan Africa Uganda inclusive has provided a detailed account of the contribution of the variations in characteristics and variations in effects of characteristics to the rural-urban gap in transactional sex among young women not in union. This study therefore provides a detailed account of the rural-urban gap in TS by variations in characteristics and variations in effects of characteristics of young women in Uganda.

Methods: The study utilized data from UDHS 2016 comprising of 1,595 records of young women (15-24 years) not in union (not currently married or living with a man). Statistical analysis was done using a Non-linear Oaxaca' Blinder Multivariate Decomposition of the logistic regression.

Results: In the results, the overall gap in rural-urban transactional sex is significantly attributed to both variations in characteristics (30.7\%) and variations in effects of characteristics (69.3\%) of young women $(p<0.05)$. Specifically, the rural-urban gap in transactional sex among young women in Uganda is attributed to variation in total children ever born (-15.2\%), age at first sex $(10.3 \%)$ and variation in effect of highest education $(-1,1014.1 \%)$ and HIV stigma (-84.3\%).

Conclusion: In order to reduce transactional sex especially among young women in rural residence, government and other development partners need to strengthen comprehensive sex-education programs aimed at creating positive attitudes towards HIV, train young women on viable economic activities together with providing them with educational opportunities aimed at delaying sex.

\section{Background}

Transactional sex (TS), a global practice (1) has been viewed by several studies to pose a significant threat to public health (2). TS has been defined as a sexual relationship involving casual or informal exchange of goods, money, gifts and services among unmarried couple in anticipation for sex (2-5). TS is associated with risky sexual behaviors, unintended pregnancy, gender based violence and HIV infection (6-10). This is because young women who engage in TS fail to decline sexual advances from a man or advocate for condom use since they feel indebted to a man after receiving favors $(7,11)$. Men on the other hand feel entitled to have sex with a woman after giving them their money which results into forced sex (12). Though there is no official global statistic on TS, a global review of 37 manuscripts across 28 countries, shows a relatively higher TS prevalence rate of $60 \%$ or higher in low- and middle-income countries compared to below $10 \%$ in high-income countries (2). In sub-Saharan Africa, a systematic review of 6 studies on TS among young women (26 years and below) shows reported TS prevalence ranging from $2.1-14 \%$ (13). Further, a global review study among 21 Sub Saharan countries shows 
Uganda having the highest (85\%) life time TS prevalence among young female youth (2). In the East African community, Uganda has the highest proportion (14.1\%) of young women (15-24 years) involved in TS (14) compared to Kenya (6.2\%) (15) and Burundi (12.2\%) (16). Proportionally in 2016, young women in Uganda involved in TS were almost twice in rural areas (16.4\%) compared to urban (8.9\%) areas (14).

Young women in low- and middle-income countries Uganda inclusive, are disproportionately more likely to engage in TS sex compared to young men (2). In Uganda, young women (15-24 years) who contribute $21 \%$ of the country's population (17) constitute an important sub-group of the population regarding reproductive health (18). High TS among young women could explain HIV prevalence among young women (15-24 years) in Uganda which is nearly four times higher than that of young men(19). The ruralurban gap in TS among young women in Uganda could also explain the high percentage of young women (15-19 years) in rural areas $(26.7 \%)$ who have begun child bearing compared to urban areas $(18.8 \%)$ in Uganda (20). This is a risk factor for maternal mortality (21) because it translates into higher teenage pregnancy and motherhood among young women in rural areas than urban areas. Previous studies on TS have alluded to several socio-economic factors that act as mediators for TS. These include Age, educational level, marital status, employment status of the young woman, household wealth index of the young woman, their religious affiliation, age at first sexual intercourse, multiple sexual partners among others $(3,22-24)$.

In order to guarantee sustainable development for any country, it is imperative that Sustainable Development Goal (SDG) 3 on "Good health and wellbeing" be achieved for all. TS being one of the significant determinants for new HIV infections, it's important to understand the detailed contribution of the variations in characteristics and variations in effects of characteristics of young women to the ruralurban differential in TS. This provides vital information needed for directing right program interventions that are locally relevant and culturally adaptable in preventing TS consequently reducing the incidence of HIV infections and other associated consequences (25). Recent studies on the determinants of TS among young women in Sub-Saharan Africa, Uganda inclusive are routinely assessed statistically using methodologies in which residence is only included as a covariate $(1,3,26,27)$. Using residence as an independent variable does not provide detailed information regarding the contribution of the variations in characteristics and variations in effect of characteristics of young women to the rural-urban gap in TS among young women in Uganda. Further, studies on the determinants of TS among young women in Sub Saharan African, Uganda inclusive have studied TS based inclusively on women of various marital status $(3,26,28,29)$. No study has explained the rural-urban gap in TS among only young women (1524 years) not in union. This study therefore provides a detailed account of the rural-urban gap in TS by variations in characteristics and variations in effects of characteristics of young women not in union in Uganda.

\section{Data And Methods}

\section{Data Source}


The study utilized the data from 2016 Uganda Demographic Health Survey (UDHS) datasets which is the most recent in Uganda. UDHS is a nationally representative cross-sectional survey implemented by the Uganda Bureau of Statistics (UBOS) in collaboration with the Ministry of Health (MOH) of the government of Uganda (20). In the 2016 UDHS, 20,880 households were selected as samples of which 18,506 Women (15-49) were successfully interviewed. To select the households for the survey, stratified two-stage cluster sampling was used. In the first stage, 697 Enumeration areas (EAs) were selected from the 2014 Uganda National Population and Housing Census (UNPHS) with 162 and 535 EAs coming from urban and rural areas respectively. However, the EA from Acholi sub-region was eliminated due to land disputes. The second stage of sampling constituted selecting households. Next, structured questionnaires were used to conduct face to face interviews for women aged 15-49 years in the sample households. There were four questionnaires administered in the 2016 UDHS: the Household Questionnaire, the Woman's Questionnaire, the Man's Questionnaire, and the Biomarker Questionnaire. However, for this study only the women's questionnaire which collected information from eligible women aged 15-49 years was used. The women's questionnaire sought the information of Background characteristics, Reproduction, Family planning, Maternal and child health, breastfeeding, and nutrition, Marriage and sexual activity, Fertility preferences, Husbands' background characteristics and women's work, STIs and HIV/AIDS, Knowledge, attitudes, and behaviors related to other health, Adult and maternal mortality, Domestic violence and Early childhood development (20). We confined the analyses to the 1,595 young women (15-24 years) who were not in union (not currently married or living with a man).

\section{Variables And Their Measurement}

\section{Dependent variable}

The dependent variable is Transactional Sex, which is determined in the 2016 UDHS by a binary outcome question: In the past 12 months, have you had sex or been sexually involved with anyone because he gave you or told you he would give you gifts, cash, or anything else? Those who said yes to the question were considered to have been engaged in TS in the last 12 months and were coded 1 while those responded no were coded 0 .

\section{Independent variable}

The independent variables for this study are Age group of the respondent, Age at first sex, Total children ever born, sex of the household head, religion, respondents Occupation, HIV stigma, HIV comprehensive knowledge, highest educational level and Household wealth index. The age groups of young women in this study are 15-19 and 20-24. Age at first sex was grouped into three categories: before 15 years, 1518 years and 19 years and above. Total children ever born was grouped into four categories: no child, one child, 2 children and 3 or more children. Sex of the household head was categorized into male and female. Religion was grouped into four categories: Anglican, Catholic, Muslim and others. Others comprised of seventh day Adventist, orthodox, Pentecostal/born again/evangelical, Baha'i, Baptist, Presbyterian, mammon, Jehovah's witness, salvation army, traditional and other. Young women's occupation (working status) was grouped into three categories- not working, working in formal sector and working in informal sector. Not working was coded 0 , working in formal sector (professional/technical 
and managerial jobs) was coded 1 while working in informal sector (clerical, sales, agricultural/selfemployed, household and domestic, services, skilled manual, unskilled manual) was coded 2. HIV stigma of the respondent was categorized into either having HIV stigma or don't have HIV stigma. HIV stigma was derived from whether one would buy vegetables from a vendor who was HIV positive. Those who could not buy vegetables from a vendor who is HIV positive were considered to be having HIV stigma. HIV comprehensive knowledge was categorized into two: don't have HIV comprehensive knowledge and have HIV comprehensive knowledge. Young women were categorized having HIV comprehensive knowledge if they responded yes to any of the following three statements: reduce risk of getting HIV: have 1 sex partner only who has no other partners; reduce risk of getting HIV: always use condoms during sex; a healthy looking person can have HIV. Young women who were categorized to lack HIV comprehensive knowledge responded yes to any of the following two statements: can get HIV from mosquito bites; can get HIV by sharing food with person who has aids. The highest educational level achieved by young women was classified into four categories: no education, primary, secondary and highest (more than secondary). Household wealth index variable was recorded into five categories- lowest, second, middle, forth and highest. Household wealth index scores were derived using principal component analysis of household economic status composed of key household assets. Household wealth index was constructed using data from household assets that ranged from a television to a bicycle or car, and housing characteristics such as source of drinking water, toilet facilities, and flooring materials (20).

\section{Methods of data analysis}

Our study employed three levels of data analyses. Firstly, a descriptive summary indicating differentials in young women's characteristics was performed using frequency distribution. Secondly, difference in Transactional sex between rural and urban young women distributed according to their characteristics was performed using frequency distribution showing percentage difference. Thirdly, Nonlinear Multivariate decomposition of the logistic regression model was used to partition the rural-urban differential in TS among young women in Uganda into components attributable to variations in characteristics and variations in effect of characteristics. This logistic regression model was used because the outcome of interest (TS) was binary in nature. All the three levels of statistical analysis were undertaken using STATA 15.0. All the calculations above were weighted using standard sample weight of UDHS. All associations were deemed statistically significant at a cut-off p-value of 0.05 .

\section{Results}

Table 1 shows slightly over five-in-every nine (56\%) young women in rural residence had primary education while nearly one half $(49.3 \%)$ of young women in urban residence had secondary level as their highest educational level. The highest rural-urban differential (26.3\%) in highest educational level was at the primary level. Nearly three-in-every five (59.5\%) young women in urban residence were aged between 20-24 years. On other hand, about five-in-every ten (54.1\%) young women in rural residence were between the ages of $15-19$. Majority of the young women in urban (37.44\%) and rural $(39.2 \%)$ residences were Catholics. On the other hand, the lowest proportion of young women in urban (17.8\%) and rural (12.1\%) residences were Muslims. 
Majority of the households in urban $(60 \%)$ residence were headed by females while most of the households in rural $(53.2 \%)$ residence were headed by males. Concerning total children ever born, results in both urban (64.3\%) and rural (55.8\%) residences reveal nearly six in every 10 young women had no child. However, the proportion of young women having at least one child was generally higher in rural compared to urban residence. Results also show majority of young women in both rural $(69.3 \%)$ and urban $(61.9 \%)$ residence to have initiated sex between $15-18$ years.

Most of the young women in rural (62.0\%) and urban (62.5\%) residences worked in the informal sector while the formal sector posted the lowest percentage in both rural (6.2\%) and urban (7.8\%) residence. Results reveal the highest proportion (57.2\%) of young women in urban residence having comprehensive knowledge on HIV while majority (52.3\%) of young women in rural residence lacked comprehensive knowledge on HIV. With regard to HIV stigma, the highest proportion of young women in both rural $(70.7 \%)$ and urban $(79.2 \%)$ areas did not have HIV stigma. However, the proportion of young women who had stigma was higher $(29.3 \%)$ in rural areas compared to urban areas $(20.8 \%)$. Majority of the households in urban areas $(70.1 \%)$ were at the highest level of wealth index while in rural residence (24.4\%) majority of the households were in the fourth level of household wealth index. 
Table 1

Distribution by women's characteristics

\begin{tabular}{|c|c|c|c|}
\hline Characteristic & Urban $(n=493)$ & Rural $(n=1,102)$ & Difference (\%) \\
\hline \multicolumn{4}{|c|}{ Highest educational level } \\
\hline No education & 1.2 & 1.5 & 0.3 \\
\hline Primary & 30.6 & 56.8 & 26.3 \\
\hline Secondary & 49.3 & 34.1 & -15.2 \\
\hline Highest & 18.9 & 7.5 & -11.4 \\
\hline \multicolumn{4}{|l|}{ Age in 5 year groups } \\
\hline $15-19$ & 40.5 & 54.1 & 13.6 \\
\hline $20-24$ & 59.5 & 45.9 & -13.6 \\
\hline \multicolumn{4}{|l|}{ Religion } \\
\hline Anglican & 25.3 & 35.5 & 10.3 \\
\hline Catholic & 37.4 & 39.2 & 1.8 \\
\hline Muslim & 17.8 & 12.1 & -5.7 \\
\hline Others & 19.6 & 13.3 & -6.3 \\
\hline \multicolumn{4}{|c|}{ Sex of household head } \\
\hline Male & 40.0 & 53.2 & 13.2 \\
\hline Female & 60.0 & 46.8 & -13.2 \\
\hline \multicolumn{4}{|c|}{ Total children ever born } \\
\hline No child & 64.3 & 55.8 & -8.5 \\
\hline 1 Child & 24.8 & 27.9 & 3.1 \\
\hline 2 Children & 7.4 & 11.3 & 3.9 \\
\hline 3 and more children & 3.6 & 5.0 & 1.5 \\
\hline \multicolumn{4}{|l|}{ Age at first sex } \\
\hline Before 15 years & 15.4 & 19.2 & 3.9 \\
\hline $15-18$ years & 61.9 & 69.3 & 7.4 \\
\hline 19 Years and above & 22.8 & 12.5 & -10.2 \\
\hline \multicolumn{4}{|c|}{ Respondents Occupation } \\
\hline Not working & 29.6 & 31.9 & 2.3 \\
\hline
\end{tabular}




\begin{tabular}{|llll|}
\hline Characteristic & Urban $(\mathbf{n = 4 9 3 )}$ & Rural $(\mathbf{n = 1 , 1 0 2})$ & Difference (\%) \\
\hline Working in formal sector & 7.8 & 6.2 & -1.7 \\
\hline Working in informal sector & 62.5 & 62.0 & -0.6 \\
\hline HIV comprehensive knowledge & & & \\
\hline Don't have HIV comprehensive knowledge & 42.8 & 52.3 & 9.6 \\
\hline Have HIV comprehensive knowledge & 57.2 & 47.6 & -9.6 \\
\hline HIV stigma & & & 8.6 \\
\hline Have HIV stigma & 20.8 & 29.3 & -8.6 \\
\hline Don't have HIV stigma & 79.2 & 70.7 & 13.1 \\
\hline Household wealth index & 3.5 & 16.6 & 17.8 \\
Lowest & 4.0 & 21.8 & 16.6 \\
Second & 4.4 & 21.0 & 6.5 \\
Middle & 17.9 & 24.4 & -54.6 \\
Fourth & 70.1 & 16.1 & \\
Highest & & & \\
\hline
\end{tabular}

\section{Transactional Sex}

Transactional sex (TS) was assessed basing on a binary outcome. These was 'Yes' for being engaged in transactional sex and 'No' for no engagement in transactional sex. Figure 1 presents the distribution of young women who were engaged in transactional by type of place of residence.

\section{Figure 1 Distribution of young women (15-24) by Transactional sex}

According to Fig. 1, approximately one-in-every eleven (8.9\%, 95\% Cl: 6.7\%-11.8\%) young women in urban residence were engaged in TS compared to about four-in-every twenty-five (16.4\%, 95\%Cl: $14.4 \%-18.7 \%)$ young women in rural residence. This result leaves a significant rural-urban difference $(7.5 \%)$ in TS among young women demonstrated by non-overlapping confidence intervals $(p<0.05)$. This implies that young women from rural residence are at a higher risk of consequences associated with TS like teenage pregnancy and HIV infection.

\section{Differentials In Transactional Sex}

Table 2 presents differences in Transactional sex between young women from rural and urban residence distributed by their characteristics. 
Table 2

Difference in Transactional sex between urban and rural young women

\begin{tabular}{|c|c|c|c|c|c|c|c|}
\hline Characteristic & $\begin{array}{l}\text { Urban } \\
(n= \\
493)\end{array}$ & $\chi^{2}$ & $\begin{array}{l}\mathrm{p}- \\
\text { value }\end{array}$ & $\begin{array}{l}\text { Rural (n } \\
=1,102)\end{array}$ & $x^{2}$ & $\begin{array}{l}\mathrm{p}- \\
\text { value }\end{array}$ & $\begin{array}{l}\text { Difference } \\
\text { (\%) }\end{array}$ \\
\hline Highest educational level & & 7.368 & 0.061 & & 12.047 & 0.007 & \\
\hline No education & 0.0 & & & 5.5 & & & 5.5 \\
\hline Primary & 12.4 & & & 18.0 & & & 5.6 \\
\hline Secondary & 8.8 & & & 14.6 & & & 5.8 \\
\hline Highest & 3.9 & & & 6.3 & & & 2.4 \\
\hline Age in 5 year groups & & 5.872 & 0.015 & & 12.308 & 0.000 & \\
\hline $15-19$ & 12.5 & & & 19.0 & & & 6.4 \\
\hline $20-24$ & 6.4 & & & 12.0 & & & 5.6 \\
\hline Religion & & 2.523 & 0.471 & & 4.911 & 0.178 & \\
\hline Anglican & 9.1 & & & 19.2 & & & 10.1 \\
\hline Catholic & 6.3 & & & 13.5 & & & 7.2 \\
\hline Muslim & 13.4 & & & 13.6 & & & 0.2 \\
\hline Others & 9.3 & & & 15.0 & & & 5.7 \\
\hline Sex of household head & & 1.694 & 0.193 & 0.193 & 3.612 & 0.057 & \\
\hline Male & 13.0 & & & 18.2 & & & 5.1 \\
\hline Female & 6.1 & & & 13.0 & & & 6.9 \\
\hline Total children ever born & & 4.309 & 0.230 & & 16.880 & 0.001 & \\
\hline No child & 10.0 & & & 20.1 & & & 10.1 \\
\hline 1 Child & 6.7 & & & 9.9 & & & 3.2 \\
\hline 2 Children & 1.8 & & & 12.2 & & & 10.4 \\
\hline 3 and more children & 19.0 & & & 8.0 & & & -11.0 \\
\hline Age at first sex & & 14.530 & 0.001 & & 11.468 & 0.003 & \\
\hline Before 15 years & 18.8 & & & 24.7 & & & 5.8 \\
\hline $15-18$ years & 7.3 & & & 14.4 & & & 7.1 \\
\hline
\end{tabular}




\begin{tabular}{|c|c|c|c|c|c|c|c|}
\hline Characteristic & $\begin{array}{l}\text { Urban } \\
(n= \\
493)\end{array}$ & $x^{2}$ & $\begin{array}{l}\mathrm{p}- \\
\text { value }\end{array}$ & $\begin{array}{l}\text { Rural (n } \\
=1,102)\end{array}$ & $x^{2}$ & $\begin{array}{l}\mathrm{p}- \\
\text { value }\end{array}$ & $\begin{array}{l}\text { Difference } \\
(\%)\end{array}$ \\
\hline 19 Years and above & 6.3 & & & 10.1 & & & 3.8 \\
\hline Respondents Occupation & & 2.159 & 0.340 & & 7.642 & 0.022 & \\
\hline Not working & 6.9 & & & 16.4 & & & 9.6 \\
\hline Working in formal sector & 4.1 & & & 6.6 & & & 2.5 \\
\hline Working in informal sector & 10.4 & & & 16.3 & & & 5.9 \\
\hline $\begin{array}{l}\text { HIV comprehensive } \\
\text { knowledge }\end{array}$ & & 0.701 & 0.402 & & 4.224 & 0.040 & \\
\hline $\begin{array}{l}\text { Don't have HIV } \\
\text { comprehensive knowledge }\end{array}$ & 10.7 & & & 18.5 & & & 7.8 \\
\hline $\begin{array}{l}\text { Have HIV comprehensive } \\
\text { knowledge }\end{array}$ & 7.5 & & & 12.8 & & & 5.3 \\
\hline HIV stigma & & 0.312 & 0.576 & & 6.737 & 0.009 & \\
\hline Have HIV stigma & 5.5 & & & 20.0 & & & 14.4 \\
\hline Don't have HIV stigma & 9.7 & & & 14.0 & & & 4.3 \\
\hline Household wealth index & & 5.547 & 0.236 & & 7.772 & 0.100 & \\
\hline Lowest & 5 & & & 15.0 & & & 10.0 \\
\hline Second & 9.1 & & & 21.3 & & & 12.2 \\
\hline Middle & 13.6 & & & 14.4 & & & 0.8 \\
\hline Fourth & 15 & & & 17.2 & & & 2.2 \\
\hline Highest & 7.4 & & & 18.8 & & & 4.4 \\
\hline Bolden indicates $P<0.05$ & & & & & & & \\
\hline
\end{tabular}

Findings from Table 2 demonstrate a general decrease in TS with increasing level of education from primary level onwards for young women in both rural and urban residences. However, the decrease was only statistically significant among young women from rural residence $(p<0.05)$. Further, across all levels of education, young women from rural residence had the highest proportion of TS compared to urban residence. With regard to the age group, TS significantly decreased with increase in the age group of a young woman for both residences $(p<0.05)$. In all age groups TS was higher for young women from rural residence compared to urban residence. Pertaining to religion, highest rural-urban difference $(10.1 \%)$ in TS was among young women in the Anglican denomination while the lowest difference $(0.2 \%)$ existed 
among young women in the Muslim denomination. However, the changes in TS with regard to religion were not statistically significant $(p>0.05)$ for both residences.

In relation to sex of household head, TS in both residences was higher among young women from households headed by men (urban $=13.0 \%$, rural $=18.2 \%$ ) compared to those headed by females (urban $=6.1 \%$, rural $=13.0 \%$ ). However, changes in TS with regard to household head were not statistically significant $(p>0.05)$ for both residences.

With regard to total children ever born, the highest (11.0\%) rural-urban differential in TS was among young women with at least three children ever born and lowest (3.2\%) among those with one child. Among young women with at least three children, TS was more pronounced in urban areas (19.8\%) compared to rural areas (8.0\%). However, the changes in TS with regard to total children ever born were only statistically significant among young women in rural residence $(p<0.05)$. With regard to age at first sex, results reveal a significant downward trend in TS with increase in age at first sex for both residences $(p<0.05)$. Pertaining to respondent's occupation, young women working in the formal sector had the lowest proportion of TS for both sub populations (urban $=4.4 \%$, rural $=6.6 \%$ ). Results further demonstrate the rural-urban gap in TS being highest (9.6\%) among young women not working and lowest $(2.5 \%)$ among those working in the formal sector. However, changes in TS with regard to respondents occupation were only statistically significant among young women in rural residence $(p<0.05)$. In both rural and urban residence, TS was higher among young women who lacked HIV comprehensive knowledge compared to those who had HIV comprehensive knowledge. However, only findings from rural residence were statistically significant $(P<0.05)$.

With regards to HIV stigma, results show TS being highest among young women with HIV stigma in rural residence while in urban residence, highest percentage of TS was among young women who lacked HIV stigma. However, the findings were only statistically significant in rural residence. Across all categories of wealth index, TS was insignificantly highest among young women in rural areas compared to urban residence $(P>0.05)$. However, wealth index was not included in the multivariate decomposition logistic model since it was not statistically significant at bivariate level and would not add much information in explaining the outcome variable in the final model. Therefore, the following variables were taken for further analysis at multivariate level; highest level of education, age in 5 year groups, religion, sex of household head, total children ever born, age at first sex, respondents occupation, HIV comprehensive knowledge and HIV stigma.

\section{Decomposition Of Differences In Transactional Sex}

A multivariate decomposition logistic model was used to decompose the rural-urban gap in TS between rural and urban young women attributed to variation in their characteristics/endowments (E) and variation in the effects of the predictors/coefficients (C). Tables 3 and 4 present decomposition results of the rural-urban gap in TS. 
Table 3

Summary of decomposition of Transactional sex

\begin{tabular}{|llll|}
\hline Components & Coefficient & p-value & Percent (\%) \\
\hline $\mathrm{E}$ & 0.0212 & 0.0120 & 30.7 \\
\hline $\mathrm{C}$ & 0.0477 & 0.0100 & 69.3 \\
\hline $\mathrm{R}$ & 0.0689 & 0.0000 & 100.0 \\
\hline $\begin{array}{l}\text { Note: Overall decomposition results of transactional sex; } n=1,595 ; \text { variations are attributed to } \\
\text { differences due to endowments (E) and coefficients (C); } R \text { is the total variation. The assessment is } \\
\text { based on weighted data. }\end{array}$ \\
\hline
\end{tabular}


Table 4

Decomposition of Transactional sex

Variables
Due to difference in characteristics $(E)$ value
Due to difference in coefficients (C)
Coefficient percent Coefficient $\mathrm{p}-$
value

percent

\section{Highest educational level}

No education

1.000

1.000

Primary

0.033

0.304

47.68

$-0.218$

$\mathbf{0 . 0 0 0}-316.90$

Secondary

$-0.016$

0.391

$-23.32$

$-0.346$

$0.000-502.13$

Highest

$-0.003$

0.862

$-3.96$

$-0.134$

$\mathbf{0 . 0 0 0}-195.10$

\section{Age in $\mathbf{5}$ year groups}

15-19

20-24

Religion

Anglican

Catholic

Muslim

Others

Sex of household head

Male

Female

Total children ever born

No child

1 Child

2 Children

3 and more children

Age at first sex

Before 15 years

$15-18$ years

Bolden indicates $P<0.05$
1.000

$-0.004$

0.370

$-5.11$

1.000

0.028

$0.166 \quad 40.89$
1.000

$-0.001$

0.002

0.002

1.000

0.005

0.116

7.03

$-1.15$

0.351

3.30

0.290

3.25
0.002

$0.828 \quad 3.54$

$-0.005$

$0.371 \quad-7.96$

$-0.001$

$0.847 \quad-1.98$

1.000

-

1.000

0.011

0.458

15.82 


\begin{tabular}{|c|c|c|c|c|c|c|}
\hline \multirow{2}{*}{$\begin{array}{l}\text { Variables } \\
19 \text { Years and above }\end{array}$} & \multicolumn{3}{|c|}{$\begin{array}{l}\text { Due to difference in } \\
\text { characteristics (E) }\end{array}$} & \multicolumn{3}{|c|}{$\begin{array}{l}\text { Due to difference in } \\
\text { coefficients }(C)\end{array}$} \\
\hline & 0.014 & 0.006 & 20.18 & -0.005 & 0.631 & -7.86 \\
\hline \multicolumn{7}{|l|}{ Respondents Occupation } \\
\hline Not working & 1.000 & & & 1.000 & & \\
\hline Working in formal sector & 0.001 & 0.474 & 1.43 & -0.002 & 0.704 & -3.11 \\
\hline Working in informal sector & 0.000 & 0.266 & -0.21 & -0.014 & 0.414 & -20.59 \\
\hline \multicolumn{7}{|l|}{ HIV comprehensive knowledge } \\
\hline $\begin{array}{l}\text { Don't have HIV comprehensive } \\
\text { knowledge }\end{array}$ & 1.000 & & & 1.000 & & \\
\hline $\begin{array}{l}\text { Have HIV comprehensive } \\
\text { knowledge }\end{array}$ & 0.003 & 0.249 & 3.79 & 0.005 & 0.721 & 7.08 \\
\hline \multicolumn{7}{|l|}{ HIV stigma } \\
\hline Have HIV stigma & 1.000 & & & 1.000 & & \\
\hline Don't have HIV stigma & 0.002 & 0.336 & 2.87 & -0.058 & 0.013 & -84.29 \\
\hline Constant & & & & 0.787 & 0.000 & 1142 \\
\hline Total & 0.021 & 0.012 & 30.7 & 0.048 & 0.010 & 69.3 \\
\hline
\end{tabular}

According to the results in Table 3, differences in TS between rural and urban young women were significantly attributed to both differences in the characteristics and variation effects of predictors of the two groups $(P<0.05)$. Overall, about $30.7 \%$ of the gap in TS can be attributed to differences in characteristics while $69.3 \%$ of the gap in TS can be attributed to differences in effects of predictors or coefficients between rural and urban young women.

\section{Variation due to difference in characteristics of women}

Overall, findings in Table 4 show that variation in characteristics of young women contributed approximately $30.7 \%$ to the overall rural-urban differential in TS. In other words, the rural urban gap in TS would reduce by $30.7 \%$ in the absence of the variations in the characteristics of young women.

Specifically, the rural-urban gap in TS among young women in Uganda was significantly attributed to characteristics of young women namely; total children ever born and age at first sex $(p<0.05)$. The positive percentages in the results show the proportion in which the overall gap would decrease if the differences in the characteristics of young women in the two groups were to disappear. On the other 
hand, the negative percentage shows the proportion to which the gap in TS would increase if the differences in the characteristics of women in the two groups were to disappear.

With regard to total children ever born, the difference in characteristics of young women contributed approximately $-15.2 \%$ to the overall rural urban gap in TS. Therefore, the overall gap in TS would increase by $15.2 \%$ if the variations in total children ever born among young women were to disappear. Specifically, young women who had one child, two children and 3 or more children contributed $-5.18 \%$, $-5.93 \%$ and $-4.04 \%$ respectively to the overall gap in TS compared to young women with no child. Therefore, the overall gap in TS would increase by $5.18 \%, 5.93 \%$ and $4.04 \%$ respectively if the above variations in total children ever born were to disappear. With regard to age at first sex, the difference in characteristics of young women contributed approximately $10.3 \%$ to the overall rural urban differential in TS. Therefore, the overall gap in TS would decrease by $10.3 \%$ if the differences in age at first sex were to disappear. Specifically, young women who initiated sex between 15-18 years and 19 years and above contributed $-9.9 \%$ and $20.2 \%$ respectively to the overall difference in TS compared to those who begun sex below 15 years of age. Therefore, the overall gap in TS would increase by $9.9 \%$ and reduce by $20.2 \%$ respectively if the above variations in age at first sex were to disappear

\section{Variation due to difference in effects of predictors (coefficients)}

Findings in Table 4 show that variation in the effects of characteristics (coefficients) contributed about $69.3 \%$ to the overall difference in TS between rural and urban young women. Specifically, the rural-urban gap in TS among young women in Uganda was significantly attributed to the effects in characteristics of young women namely; highest level of education and HIV stigma $(p<0.05)$. With regard to highest educational level, the variation in the effects of predictors of young women contributed approximately $1,014.1 \%$ to the overall rural-urban differential in TS. Therefore, the overall gap in TS would increase by $1,014.1 \%$ if the differences in the effects of highest education level were to disappear. Specifically, young women who had primary, secondary and highest level of education contributed $-316.90 \%,-502.13 \%$ and $-195.10 \%$ respectively to the overall gap in TS compared to young women who had no education. Therefore, the overall gap in TS would increase by $316.90 \%, 502.13 \%$ and $195.10 \%$ respectively if the above variations in the effects of highest educational level were to disappear. With regard to HIV stigma, the variation in the effects of young women who didn't have HIV stigma compared to those who had HIV stigma contributed approximately $-84.3 \%$ to the overall gap in TS. Therefore, the overall gap in TS would increase by $84.3 \%$ if the differences in the effects of young women who lacked HIV stigma compared to those who had HIV stigma were to disappear.

\section{Discussion Of Findings}

This study analyzed data from 2016 UDHS to assess the rural-urban differential in TS among young women in Uganda. The findings show that the differences in TS can be attributed to both variation in characteristics (endowments) and variation in effects of characteristics (coefficients). In particular, the compositional variation in rural and urban young women are noted in characteristics namely total children ever born and age at first sex. Variation in the effect of characteristics (coefficient) also 
contributed to the gap for example variation in highest educational level and HIV stigma contributed to differences in TS between rural and urban young women in Uganda.

The characteristic that had major contribution to the overall gap in TS between rural and urban young women was age at first sex. Findings show that the rural-urban gap in TS among young women would reduce by $10.3 \%$ if the variation in age at first sex disappeared. This is possibly because a higher proportion of young women from rural residence begun sex at an earlier age than those from urban residence consequently leading to higher TS in rural residence compared to urban residence. Young women who initiated sex at an earlier age were also significantly more likely to engage in TS than those who initiated sex at a later age. Plausible reason for the above is that young women who have sex at an early age are more likely to get pregnant which consequently leads to increased demand of personal needs thus pushing them to engage in TS. This finding is consistent with the findings conducted in Malawi (30) and in Post-conflict Liberia (6) which showed young women who initiated sex at an earlier age being more likely to engage in TS.

Variation in total children ever born was also found in this study to have contributed negatively to the overall difference in TS between young women in rural and urban residence. The findings show that the disparity in rural-urban TS would increase by $15.2 \%$ if the variation in total children ever born disappeared. However, the protective advantage of having children would decrease with increase in the total number of children ever born. This finding is consistent with findings in a study by (8) which showed an increase in the odds of TS with increase in the number of children ever born. This is because young women with children get under considerable financial strain since they are just completing school and entering the labor force thus making them economically unstable (8).

Variation in the effect of highest educational level of a young woman, was also found to contribute negatively to the gap in TS between rural and urban young women in Uganda. This means having higher levels of education protect a young woman from engaging in TS. The possible explanation for this is that education empowers young women with information regarding negative consequences associated with TS and thus they tend to avoid it. Education also keeps young women busy and thus reduces the time they would be tempted to engage in Transactional sexual affairs. This findings are consistent with many studies that have shown higher levels of education being associated with decreased TS $(6,22,31)$. However, the results from this study contradict the findings in a study on alcohol use and TS among women in South Africa (28) which showed a positive association between TS and increasing level of education.

With regard to HIV stigma, findings from decomposition analysis showed a negative contribution of the variation in the effect of HIV stigma to rural-urban gap in TS. The possible reason behind this finding is that young women who don't possess HIV stigma are free to seek Adolescent Sexual and Reproductive Health services. This empowers them with useful information on how to lead a safe sexual lifestyle. This results are consistent with findings in Uganda (32) that showed fisher folks in Uganda who had internalized HIV stigma having higher odds of TS than those who didn't. 


\section{Limitations And Strength}

This study is not without limitations. Data for this study was from a cross sectional survey from the 2016 UDHS. Therefore it is limited in establishing causal relations between TS and the dependent variables. However, efforts have been made asses the relative contribution of the explanatory variable available in the 2016 DHS dataset in explain the rural-urban gap in TS among young women in Uganda. However, the major strength of this study is that, it uses a nationally representative data and multivariate method to decompose the rural urban gap in TS among young women in Uganda.

\section{Conclusions}

To the best of our knowledge, this is the first national study to provide a detailed account to the ruralurban gap in TS by variation in characteristics and variation in effects of characteristics of young women. The finding of this study has revealed that both variation in characteristics and variation in effects of characteristics of young women are responsible for the rural-urban gap in TS among young women in Uganda. Specifically, the rural-urban gap in TS is significantly attributed to differences in characteristics of young women namely; total children ever born, age at first sex and difference in effects of characteristics of young women namely: HIV stigma and highest education level. Therefore, in order to reduce transactional sex especially among young women in rural residence, government and other development partners need to strengthen comprehensive sex-education programs aimed at creating positive attitudes towards HIV, train young women on viable economic activities together with providing them with educational opportunities aimed at delaying sex.

\section{Abbreviations}

Acquired Immuno-Deficiency Syndrome (AIDS), DHS: Demographic Health Survey; EA: Enumeration area; HIV: Human Immune Virus; STI: Sexually Transmitted Infection; TS: Transactional Sex; UBOS: Uganda Bureau of Statistics; UDHS: Uganda Demographic Health Survey; (UNPHS): Uganda National Population and Housing Census.

\section{Declarations}

\section{Ethics approval and consent to participate}

The data used in the investigation was secondary from 2016 UDHS datasets, thus approval for using the data was sought and granted online from the DHS program website

(https://www.dhsprogram.com/data/available-datasets.cfm). Permission was granted to download and use data for the study.

\section{Consent for publication}

No consent for publication 


\section{Availability of data and materials}

The data used in the analysis of this study are freely available in public domain from the DHS Program website (https://www.dhsprogram.com/data/available-datasets.cfm). We specifically used the UGIR70FL, which is individual Recode with data on women (15-49) with completed interviews in Uganda for the 2016 UDHS.

\section{Competing interests}

Authors declare that they have no competing interests

\section{Funding}

Authors received no funding for the study

\section{Author's contribution}

MKM conceptualized the area of study. VO developed the study, reviewed the literature, acquired the data, analyzed, interpreted the results and drafted the manuscript. RW \& MKM reviewed, provided technical guidance to the study. VO, RW \& MKM approved the final manuscript.

\section{Acknowledgements}

The authors are grateful to measure DHS for granting the permission to use 2016 UDHS data. The authors also appreciate Stephen Ediru for his technical assistance in the analysis of the dataset.

\section{Author's information}

Vincent Okotel is a master's student of Masters of Science in Population and Reproductive health at the Department of Population Studies, School of Statistics and Planning, College of Business and Management Sciences, Makerere University.

Robert Wamala (PhD) is an Associate Professor at the School of Statistics, College of Business and Management Studies, Makerere University. He is also the Deputy Director at the Directorate of Research and Graduate Training (DRGT) at Makerere University.

Martin Kayitale Mbonye (PhD) is a Lecturer at the Department of Population Studies, School of Statistics and Planning, College of Business and Management Sciences, Makerere University.

\section{References}

1. Wamoyi J, Ranganathan M, Kyegombe N, Stoebenau K. Improving the Measurement of Transactional Sex in Sub-Saharan Africa: A Critical Review. Acquir Immune Defic Syndr. 2019;80(4):367-74. 
2. Averdijk M, Valdebenito S, Eisner MP, Krisch M. Sex Trade Among Youth: A Global Review of the Prevalence, Contexts and Correlates of Transactional Sex Among the General Population of Youth. Adolesc Res Rev. 2019;1-21.

3. Chatterji M, Murray N, London D, Anglewicz P. The Factors Influencing Transactional Sex Among Young Men and Women in 12 Sub-Saharan African Countries. 2004.

4. Ranganathan M. Transactional sex among young women in rural South Africa: socio-demographic factors, motivations and association with HIV infection [Internet]. University of London; 2015. Available from: http://researchonline.Ishtm.ac.uk/2095793/

5. Jones CS. The Extent and Effect of Sex Tourism and Sexual Exploitation of Children on the Kenyan Coast The Extent and Effect of Sex Tourism and Sexual Exploitation of Children on the Kenyan Coast. 2006.

6. Okigbo CC, Mccarraher DR, Chen M, Pack A. Risk Factors for Transactional Sex among Young Females in Post- Conflict Liberia. African J Reprod Heal Sept 2014. 2014;18(3):133-41.

7. Soler-hampejsek E, Duby Z, Hewett PC. "When He Asks for Sex, YouWill Never Refuse": Transactional Sex and Adolescent Pregnancy in Zambia. Stud Fam Plann. 2019;0(0):1-14.

8. Wet N De, Frade S, Akinyemi J, Spencer G. Extra mouths to feed: The odds of young mothers engaging in transactional sexual relationships in South Africa. Cogent Soc Sci [Internet]. 2018;4(1482986):1-12. Available from: https://doi.org/10.1080/23311886.2018.1482986

9. Dunkle KL, Wingood GM, Camp CM, DiClemente RJ. Economically Motivated Relationships and Transactional Sex Among Unmarried African American and White Women: Results from a U.S. National Telephone Survey. Public Health Rep. 2010;125(4):90-100.

10. Dunkle KL, Levin J. Transactional sex and economic exchange with partners among young South African men in the rural Eastern Cape: prevalence, predictors, and associations with gender-based violence. Soc Sci Med. 2007;65(6):1235-48.

11. Stoebenau K, Nixon SA, Rubincam C, Willan S, Zembe YZN, Tsikoane T, et al. More than just talk: the framing of transactional sex and its implications for vulnerability to HIV in Lesotho, Madagascar and South Africa. Global Health [Internet]. 2011;7(1):34. Available from: http://www.globalizationandhealth.com/content/7/1/34

12. Maganja RK, Maman S, Groves A, Mbwambo JK. Skinning the goat and pulling the load: transactional sex among youth in Dar es Salaam , Tanzania. AIDS Care. 2007;19(September):97481.

13. Wamoyi J, Stobeanau K, Bobrova N, Abramsky T, Watts C. Transactional sex and risk for HIV infection in sub-Saharan Africa: a systematic review and meta-analysis. J Int AIDS Soc [Internet]. 2016;19(20992):1-16. Available from: http://www.jiasociety.org/index.php/jias/article/view/20992

14. Uganda Bureau of Statistics (UBOS), ICF. Uganda: Standard DHS, 2016 [Dataset] UGIR7BFL.DTA. IPUMS Demographic and Health Surveys (IPUMS DHS), version 7, IPUMS and ICF [Distributors] [Internet]. Kampala, Uganda and Rockville, Maryland, USA: IPUMS and ICF [Distributors]; 2018 [cited 2019 Oct 19]. Available from: https://www.dhsprogram.com/data/dataset_admin/index.cfm 
15. Kenya Bureau of Statistics, ICF. Kenya: Standard DHS, 2014 [Dataset] KEIR72FL. IPUMS Demographic and Health Surveys (IPUMS DHS), version 7, IPUMS and ICF [Distributors]. Nairobi, Kenya and Rockville, Maryland, USA: ICF [Distributor]; 2014.

16. Ministère à la Présidence chargé de la Bonne Gouvernance et du Plan [Burundi] (MPBGP), et ICF. Troisième Enquête Démographique et de Santé 2016-2017 [Dataset] BUIR70FL. IPUMS Demographic and Health Surveys (IPUMS DHS), version 7, IPUMS and ICF [Distributors]. Bujumbura, Burundi: ISTEEBU, MSPLS, et ICF; 2017.

17. Uganda Bureau of Statistics. National Population and Housing Census 2014- Main Report. Kampala, Uganda; 2016.

18. Thapa NR. Factors influencing the use of reproductive health services among young women in Nepal: analysis of the 2016 Nepal demographic and health survey. Reprod Health. 2020;17(102):112.

19. Ministry of Health Uganda. Uganda Population-based HIV Impact Assessment (UPHIA) 2016-2017: Summary Sheet: Preliminary Findings.

20. Uganda Bureau of Statistics (UBOS), ICF. Uganda Demographic and Health Survey 2016. Kampala, Uganda and Rockville, Maryland, USA; 2018.

21. Mbonye AK. Risk Factors Associated with Maternal Deaths in Health Units in Uganda. African $J$ Reprod Heal Introd [Internet]. 2001;5(3):47-53. Available from: https://www.jstor.org/stable/3583322

22. Choudhry V, Ambresin A, Nyakato VN. Transactional sex and HIV risks - evidence from a crosssectional national survey among young people in Uganda. Glob Health Action [Internet]. 2015;8(127249):1-12. Available from: https://doi.org/10.3402/gha.v8.27249

23. Akwara PA, Madise NJ, Hinde A. Perception of risk of HIV / AIDS and Sexual Behaviour in Kenya. J biosoc Sci. 2003;35.

24. Stoebenau K, Heise L, Wamoyi J, Bobrova N. Revisiting the understanding of " transactional sex " in sub-Saharan Africa: A review and synthesis of the literature. Soc Sci Med [Internet]. 2016;168(2016):186-97. Available from: http://dx.doi.org/10.1016/j.socscimed.2016.09.023

25. Stierhout L. The influence of different motivations for having sex on condom use of South-African adolescents in the Limpopo province. 2014.

26. Choudhry V, Nyakato VN. Transactional sex and HIV risks - Evidence from a cross-sectional national survey among young people in Uganda. Glob Health Action. 2015;8(27249).

27. Ambresin A, Kyagaba E, Choudhry V. Giving or Receiving Something for Sex: A Cross-Sectional Study of Transactional Sex among Ugandan University Students. PLoS One. 2014;9(11).

28. Magni S, Christofides N, Johnson S, Weiner R. Alcohol Use and Transactional Sex among Women in South Africa: Results from a Nationally Representative Survey. PLoS One. 2015;10(12):1-15.

29. Gichane MW, Moracco KE, Pettifor AE, Zimmer C, Maman S, Phanga T, et al. Socioeconomic Predictors of Transactional Sex in a Cohort of Adolescent Girls and Young Women in Malawi : A Longitudinal Analysis. AIDS Behav [Internet]. 2020; Available from: https://doi.org/10.1007/s10461020-02910-5 
30. Longwe MB. The extent and risk factors for transactional sex among young people, in urban informal settlements in Blantyre, Malawi Submitted by. Johannesburg; 2015.

31. Akoku DA, Tihnje MA, Vukugah TA, Tarkang E, Mbu RE. Socio-economic vulnerabilities and HIV: Drivers of transactional sex among female bar workers in Yaounde. PLoS One. 2018;13(6):1-13.

32. Sileo KM, Bogart LM, Wagner GJ, Musoke W, Mukasa B, Wanyenze RK, et al. HIV fatalism and engagement in transactional sex among Ugandan fisherfolk living with HIV. SAHARA-J J Soc Asp HIV/AIDS [Internet]. 2019;16(1):1-9. Available from: www.tandfonline.com/loi/rsah20

\section{Figures}

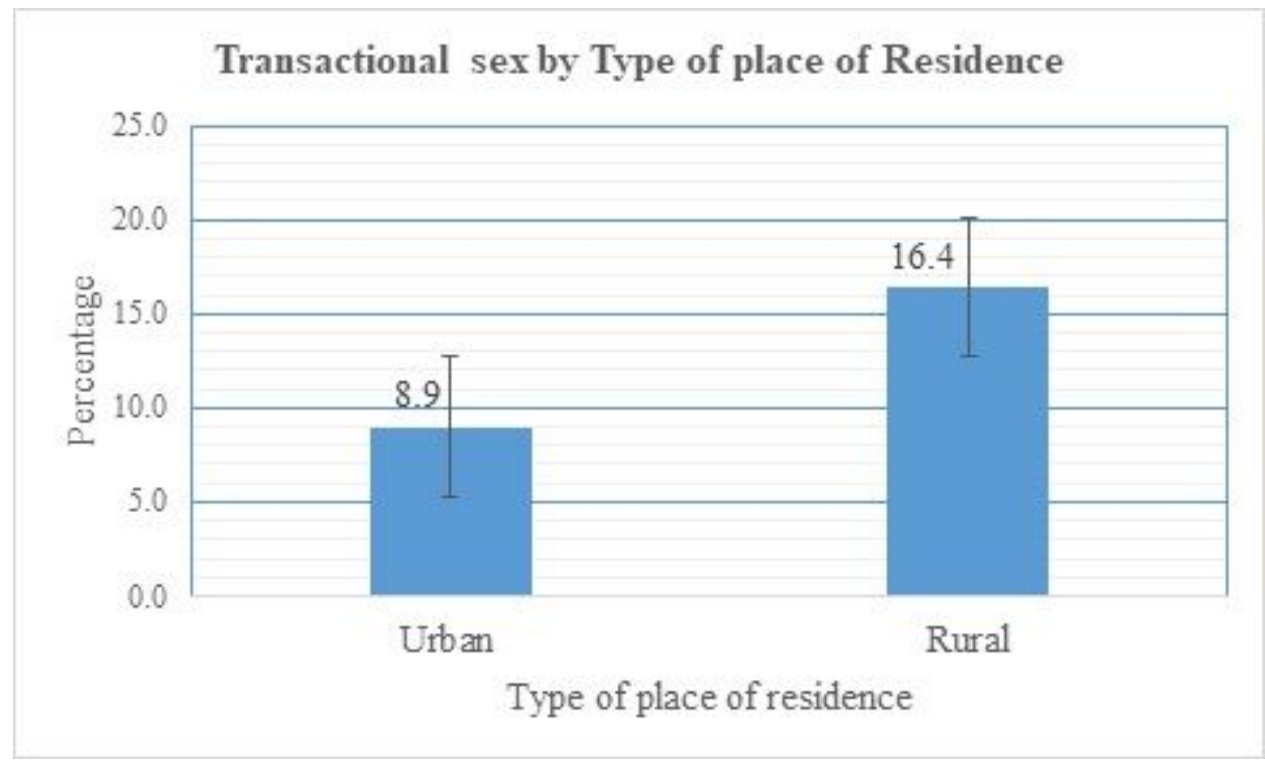

Figure 1

Distribution of young women (15-24) by Transactional sex 